\title{
The Clock de Christian Marclay: en torno a los sistemas de orientación, alteración y medida del tiempo
}

\section{The Clock by Christian Marclay: on the Systems of Orientation, Alteration and Measurement of Time}

\author{
Sandra Elisa Molina Franjola \\ Investigadora independiente, Universidad de Chile. Santiago, Chile. \\ sandramolinaf@gmail.com
}

\section{Resumen}

A partir de la obra The Clock (2010) de Christian Marclay, -que consta de un montaje audiovisual de 24 horas de escenas alusivas al tiempo-, se interroga la función de los sistemas de representación temporal como parte del lenguaje que articula el arte en la actualidad. Bajo la premisa de que el ingreso del tiempo en el arte hace visible una serie de paradojas respecto de nuestra propia relación con el tiempo (entendido como tiempo lineal, administrado y mediado técnicamente), se pregunta por la disposición actual -alterada- del tiempo como sistema de orientación en el mundo, como material de obra y como parte constituyente de la experiencia.

Palabras clave: tiempo en el arte, alteración del tiempo, orientación en el mundo, reloj, experiencia del tiempo.

\section{Abstract}

From the piece The Clock (2010) by Christian Marclay -which consists in a 24-hour audiovisual montage of alluding time scenes-, the function of time representation systems is questioned as part of the language that articulates art today. Under the premise that the entry of time in art makes visible a series of paradoxes about our own relationship with time (understood as linear, administered and technically mediated time), it is asked about the current -altered- disposition of time as an orientation system in the world, as art material and as a constituent part of the experience.

Keywords: Time in Art, Alteration of Time, Orientation in the World, Clock, Time Experience. 
En el año 2010, el artista Christian Marclay presentó en la galería White cube de Londres una obra audiovisual titulada The Clock. La propuesta consistía en el montaje de diversos extractos de series y películas provenientes de la industria del cine y televisión que hacían alusión al tiempo, ya sea mediante la imagen del reloj, diálogos alusivos al tiempo o acciones que permitían articular una coordinación visual en la que se representaba las veinticuatro horas del día (fig. 1). Todos los fragmentos fueron cuidadosamente sincronizados para calzar el tiempo exacto del movimiento de las manillas del reloj, de manera que la hora que marcaba la obra mediante las referencias visuales y sonoras era exactamente la misma que la hora oficial del país en el que se exhibía. Terminada las veinticuatro horas de proyección, la obra volvía a empezar, generando un sinfín.

La irrupción de esta propuesta en el ámbito del arte contemporáneo deja entrever no solo que el tiempo puede ser concebido como un material de obra dentro de los lenguajes actuales con los que se producen piezas de arte. También releva la existencia de una disposición técnica en la actualidad, que permite que dichos lenguajes se conciban en tiempo real, es decir, como tiempos técnicos que emulan la temporalidad cotidiana. Tomando en cuenta los vínculos que se establecen entre la producción de obra y el contexto en el que se gesta, la propuesta de Marclay aprovecha la disposición temporal administrada y mediatizada de la actualidad - caracterizada por trasladar la concepción temporal desde la experiencia hacia la representación- para reflexionar y exhibir un modo de relación con el tiempo. Esta concepción temporal mediada por la técnica -el tiempo administrado- altera la percepción del tiempo al propiciar una relación de carácter paradojal, esto es, la experiencia cotidiana que tenemos del tiempo mediante relojes y calendarios es una relación que se establece con su representación, mas no con la experiencia temporal misma. Sin embargo, creemos organizar el tiempo mediante dichos sistemas de representación.

Si pensamos entonces que The Clock hace evidente el modo ambiguo en el que establecemos actualmente una relación con el tiempo, cabe preguntar: ¿qué es lo que ponen de manifiesto los sistemas de medida del tiempo en la actualidad? ¿De qué modo la poética temporal de esta obra permite pensar y cuestionar la medición del tiempo como un sistema de orientación en el mundo? Y por último, ¿cómo es que el ingreso del tiempo en el arte contemporáneo -dado este ejemplo- nos permite analizar las condiciones actuales de la experiencia temporal?

Si pensamos el tiempo desde la concepción moderna como subjetivo y lineal, ${ }^{1}$ esto es, una concepción temporal irreversible que es imposible de retener o intervenir, despojada de parámetros objetivos de cuantificación -tal como plantea Gilles Deleuze, un tiempo que "ha salido de sus goznes"(42)-, al momento de pensar este tiempo lineal en el contexto de la vida cotidiana o la problematización en las obras de

1 En referencia a la definición del tiempo kantiano como forma de la sensibilidad necesaria para que se dé la experiencia del mundo expuesta en la estética trascendental. 
FIGURA 1

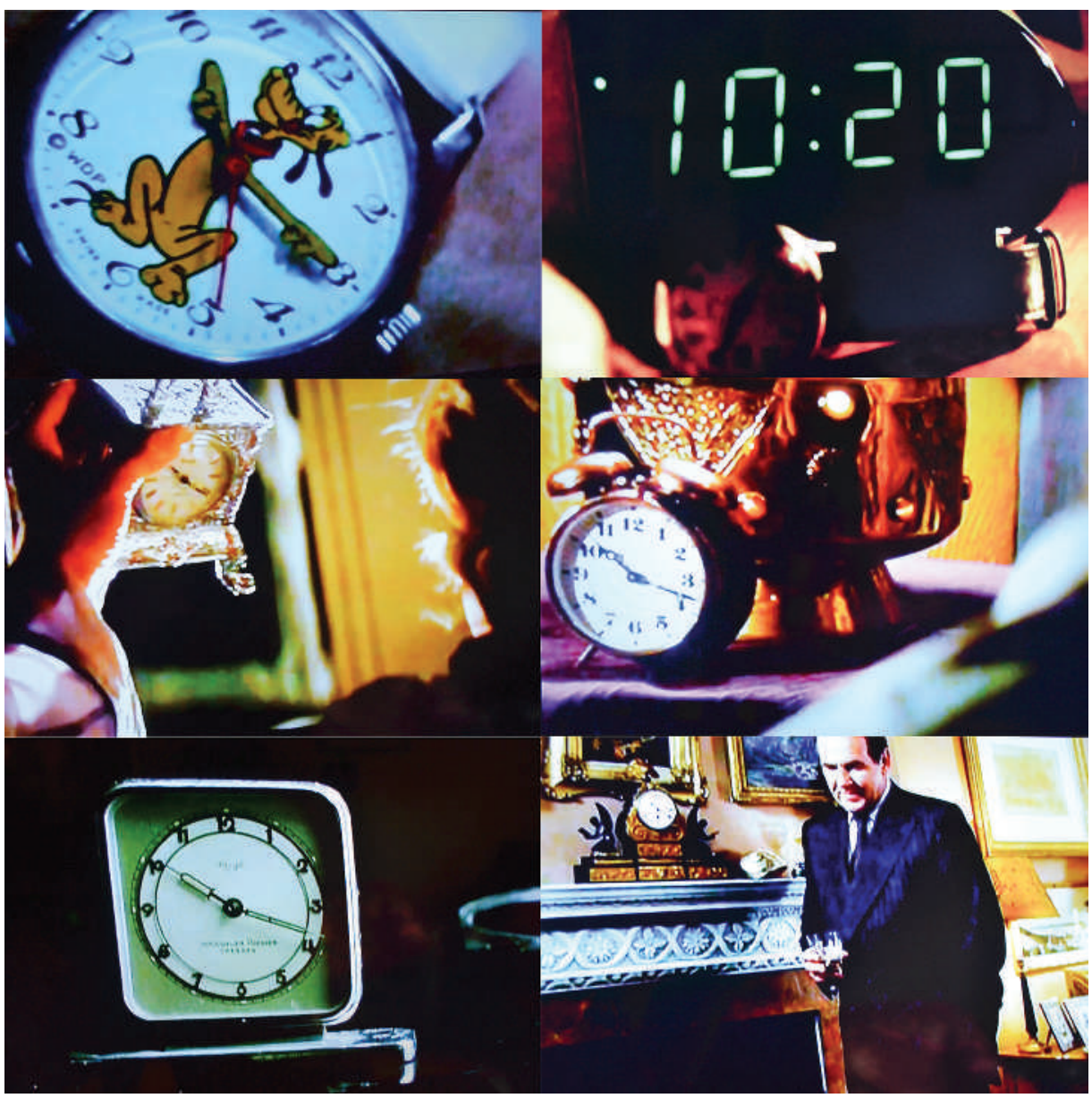

Christian Marclay, The Clock, obra audiovisual de veinticuatro horas. 2010. Fragmentos de fotogramas.

arte se produce una vinculación paradójica entre el tiempo subjetivo y la necesidad de organización del tiempo. Esto se produce porque la misma concepción temporal kantiana, que se desliga de la contención objetiva al proyectarse al interior del sujeto, es la que genera la noción de un fluir de tiempo lineal imposible de retener, y que por lo mismo provoca la necesidad de buscar medios para organizar lo que en él sucede, aun cuando sea imposible encauzar el tiempo como tal. He ahí la paradoja: el mismo tiempo, concebido como una forma de la sensibilidad necesaria para que se dé la experiencia y despojado de ataduras objetivas, es el que se intenta organizar debido a su naturaleza incontenible; y es por ese requerimiento de limitación y administración que se genera una serie de estrategias de representación del paso del tiempo. Sin embargo, esa proliferación de representaciones como parámetros de 
orientación que hacen del tiempo un factor que se puede anticipar, acortar, multiplicar, configurar, etcétera, implica la alienación del tiempo como tal, es decir, más allá de ser manipulable, el tiempo solo puede ser sentido. Bajo esta óptica, las obras de arte que reflexionan sobre la magnitud temporal mediante sus poéticas visuales, en este caso específicamente bajo el ejemplo de la obra de Marclay, se vinculan con ese punto de desencuentro entre el tiempo y su representación, es decir, entre el tiempo que se intenta administrar -que se mantiene emancipado de todo dispositivo de contención- y las mediciones, estandarizaciones y calendarizaciones, que generan una relación con el tiempo burocratizada, y por ende, desafiliada de la temporalidad de la experiencia.

\section{El tiempo como orientación en el mundo}

La experiencia del tiempo se ve afectada por todos los componentes que rodean y componen la vida, esto es, los órdenes de trabajo, las tecnologías emergentes, las redes comunicacionales, todos son factores que inciden en la manera en que se experimenta subjetivamente el tiempo. Por lo mismo, existiría una correspondencia entre la experiencia del tiempo y las modificaciones y avances que la tecnología genera, interviniendo en amplios aspectos de la vida cotidiana. Las personas buscan parámetros de medida no solo para conmensurar distancias y productividad, sino también para medir el tiempo, que así se vuelve un factor de orientación en el mundo. Pero, en el fondo del problema del requerimiento de parámetros de orientación, está la inherente desorientación que impulsa esta búsqueda de medidas y conmensuraciones de los fenómenos y factores que componen la vida. De otro modo, si el ser humano estuviese completamente situado en el mundo, no requeriría de un sistema de acomodo de magnitudes de la naturaleza. En este sentido, hombres y mujeres se encuentran siempre en un proceso de adaptación al medio, el que además de someterse a cambios naturales, cambia por factores técnicos, sociales y políticos derivados del contexto (pos)moderno, globalizado y neoliberal de la actualidad.

Bernard Stiegler plantea que "la historia del hombre es la de la técnica como proceso de exteriorización en el que la evolución técnica está dominada por unas tendencias con las que las sociedades humanas deben negociar constantemente" (8). El sistema técnico, caracterizado por estar en constante evolución, agota a los otros sistemas que estructuran la "cohesión social". Se daría entonces un proceso de ajuste constante entre las innovaciones técnicas y la tradición que estructura las sociedades humanas, debido a que "el devenir técnico es originariamente un desgarramiento" (Stiegler 8) en el cual la "tecnogénesis" se va reapropiando de la "sociogénesis", haciendo que ambos procesos sean irreductibles. Dicho de otro modo, bajo los requerimientos evolutivos de las sociedades, los cambios técnicos van generando nuevos modos de interacción social que hacen caducar a los anteriores, ya que "dependiendo de su 
alcance, el cambio técnico conmociona más o menos los parámetros definidores de toda cultura" (Stiegler 8) y, por ende, del sistema social y su concepción temporal.

Por otra parte, Stiegler define que las cardinalidades "oriente y occidente designan experiencias singulares de la desorientación" (Stiegler 9). Esto es, refieren a puntos que, al distinguir referencias específicas de ubicación en el globo, implican un ocultamiento de la desorientación basal del hombre. Si bien advierte que las referencias geográficas se ajustan en el tiempo según condiciones sociales y técnicas, a la larga la experiencia de una supuesta orientación no hace más que reformar la desorientación. Lo fundamental del asunto es que la presumida orientación solo tiene lugar a partir de una experiencia del mundo; sin embargo, la arbitrariedad de los modos de disposición del globo, simplemente, desplazan la desorientación:

\begin{abstract}
Esta cardinalidad es hoy aquello que no llega a constituirse y que nos impone el sufrimiento de la desorientación como tal. Eso se debe en gran parte a la velocidad que el desarrollo técnico ha ido adquiriendo desde la revolución industrial y que no deja de aumentar, ahondando dramáticamente el retraso entre sistema técnico y organizaciones sociales como si, al parecer imposible la negociación, tuviera que consumarse la separación (Stiegler 10).
\end{abstract}

Así, el autor caracteriza el contexto actual como un estado de desorientación suscitado por la velocidad con la que el desarrollo técnico ha generado cambios. El trastorno social que eso conlleva y la dificultad para rearticular los parámetros de referencia que antaño servían para emplazarse en el mundo implican una aparente disociación entre el sistema técnico y la organización social. Si, como plantea el autor, la temporalidad humana proviene de la desorientación originaria, ${ }^{2}$ y la vinculación con la técnica ha permitido, de un tiempo a esta parte, estabilizar socialmente la desorientación, en la actualidad, dado el desajuste técnica-sociedad, la desorientación ha quedado al descubierto, al igual que los esquemas que delimitan la temporalidad. El tiempo excede los parámetros que se han impuesto para su medición; sin embargo, aun cuando se hayan distanciado los avances técnicos de las dinámicas sociales, el tiempo sigue siendo un factor fundamental para la experiencia del mundo, ya sea si proviene de la desorientación originaria o si es un factor propenso a estandarizarse en pos de la orientación.

Por su parte, el sociólogo Norbert Elias comprende el tiempo como un fenómeno que depende de organizaciones sociales, las cuales son necesarias para que el hombre se entienda a sí mismo. De este modo, la medición del tiempo es uno de los más importantes parámetros de orientación que precisa. Elias explica que los tiempos entendidos filosóficamente como objetivos o subjetivos, aunque opuestos, participan de supuestos fundamentales comunes, que consisten en que el tiempo se presenta como un dato natural, ya sea de la creación de la naturaleza o bien de la naturaleza

2 "Quienes oponen técnica y civilización no soportan que [...] el hombre sea un ser proteico, sin cualidad, y que la temporalidad [...] proceda de esa carencia originaria, de esta desorientación originaria" (Stiegler 9). 
humana (Elias 30). Bajo estos predicados, Elias propone que el tiempo es un medio creado por los hombres para orientarse, y a su vez, una institución de orden social. Tanto Stiegler como Elias, entonces, reconocen en el tiempo un modo de experiencia del mundo. Mientras para el primero, el tiempo es un factor originario que proviene de la desorientación humana, para el segundo, el tiempo es un modo de orientación en el mundo, y por lo mismo, precisa de parámetros.

La forma de representación del tiempo, aun cuando bajo la conciencia moderna sea lineal, subjetiva e irreversible, se grafica en códigos repetibles, en ciclos renovados que avanzan, siendo cada uno distinto del otro, pero a la vez, encapsulado en los mismos parámetros.

La sucesión irrepetible de los años representa, en este caso y de modo simbólico, la secuencia irrepetible de un proceso social y natural. Así resulta útil como medio para orientarse en el continuum grande y cambiante del mundo al mismo tiempo natural y social. Así pues, días y meses del calendario se constituyen en el modelo repetible de la irrepetible secuencia de hechos (Elias 31).

La medición del tiempo surge en función del requerimiento de un patrón que demarque y limite en fragmentos conmensurables el continuum temporal. El pensamiento sobre el tiempo desde los esquemas sociales que lo encauzan en horas, meses y años proviene de una pretensión de anticipación y orientación de lo indeterminable. El modo en que se delimita el tiempo demarca, a su vez, una forma social de relación con el mundo desde los diversos patrones temporales. Elias afirma que la importancia de la orientación en el tiempo radica no solo en que determina una forma de comprensión del mundo, sino también en que es fundamental para que el hombre se entienda a sí mismo. Por lo tanto, si pensamos que ha habido diversas formas de comprensión del tiempo, significa que también existen diferentes formas de orientación en el mundo y, por lo tanto, de comprensión del ser humano.

En este ámbito, Jacques Attali, expone una revisión de los aparatos que se han usado para medir el tiempo, argumentando que es posible hacer varios relatos del tiempo en función de su técnica de medida. Tanto Elias como Attali parten de la premisa de que cada sociedad formula un tiempo propio, articulando a su vez un sentido histórico particular:

Cada sociedad tiene su tiempo propio y su historia; cada una se sitúa en una teoría de la historia y se organiza alrededor de un dominio del calendario; toda cultura se construye alrededor de un sentido del tiempo; todo trabajo del hombre es pensado como un tiempo cristalizado, como una aceleración del que sigue la naturaleza (Attali 10).

De este modo, el autor reflexiona en torno a dos formas del tiempo que se establecen actualmente, generando una triangulación entre el ser humano, la técnica y el tiempo. En la primera, el ser humano es utilizado por el tiempo, poniéndose al servicio de una 
uniformización, codificación y programación, como si se tratara de la disposición de otra máquina, de modo que la vida estaría regida por los horarios y los ritmos de la máxima producción posible. Así, la comprensión técnica del tiempo somete a hombres y mujeres a un transcurso estandarizado, haciendo del ser humano un factor más de producción y anulando la cualidad y singularidad vital. En la segunda forma del tiempo que propone Attali, el hombre inventa el tiempo, es decir, trasforma y utiliza a la máquina en pos de la organización de su vida, por lo que la técnica genera tiempo para entregarlo al ritmo personal de organización. Al revisar estos planteamientos, lo importante es reconocer de qué manera, a partir de los avances técnicos, la máquina es un elemento fundamental para dirigir el tiempo, ya sea en función de ella o gracias a ella. Ese traslado del tiempo del sujeto a la máquina o al instrumento, propicia lo denominado anteriormente como alteración del tiempo, ya que al ser "trasladado" a los elementos manipulables, el tiempo se vuelve un bien disponible, lo cual implica alienarlo del sujeto.

Attali, explica que el elemento que realmente revoluciona la industria no es el ferrocarril ni la máquina textil, sino el reloj, ya que debido a este se configura una forma de administración del trabajo y una concepción de mundo en base a la mediación técnica del tiempo. De acuerdo con su formulación, "el tiempo de las Máquinas puede comenzar ahí donde ha nacido el reloj” (168). La preponderancia del reloj para organizar la vida moderna -incluso la actual-, es un factor que determina técnicamente una forma de experiencia del mundo. Ante este problema, George Woodcock plantea que la orientación en el tiempo mediante el reloj, más que organización social, es un componente de tiranía mecánica (Woodcock 65). Ello se debe a que explota a los trabajadores, sometiéndolos al tiempo ya no como un elemento de la vida natural sino como un bien intercambiable. El autor argumenta que el movimiento mecánico del reloj hace que el hombre pierda el control de su invención, siguiendo el ritmo autoimpuesto, para convertirse en un criado del tiempo. Si bien la postura de Woodcock es más bien radical respecto de la figura del reloj, parte de la misma reflexión desde la que Attali formula las dos formas del tiempo: la idea de que existe una relación indisoluble entre la experiencia del tiempo y la técnica moderna. Por lo mismo, cabe preguntar ¿hasta qué punto la dependencia de los parámetros temporales implica un sometimiento del hombre a sus propias imposiciones, o bien, una referencia necesaria para desarrollar la vida bajo las condiciones técnicas actuales? El rendimiento de esta pregunta intenta problematizar no el establecimiento de una posición respecto del papel que juegan los parámetros temporales en la sociedad, sino más bien, que el carácter arbitrario de dichos sistemas de medida puede ser el origen de múltiples interrelaciones -sociales, culturales, comunicacionales, tecnológicas, económicas, etc.- basadas en la cuantificación del tiempo. Lo relevante, entonces, es determinar que los parámetros temporales sirven para coordinar diversos sistemas que se van concertando a medida que aumentan las interconexiones entre diversos campos disciplinares. 
Retomando los argumentos de Elias, el autor propone que en las sociedades desarrolladas el símbolo del tiempo se vuelve un factor cada vez más abstracto, ya que se complejizan las interdependencias entre dinámicas sociales, medios de comunicación, desarrollos técnicos y tránsitos digitales. Cada vez es necesario ir ajustando y precisando los sistemas de medida del tiempo debido a que los requerimientos sistémicos se vuelven cada vez más exactos. Por lo mismo, la noción temporal parece ajustarse a medios cada vez más veloces, con lo que se desarrollan nuevas formas de entender y experimentar el tiempo desde "el tiempo real", la instantaneidad y la preponderancia del reloj, entre otras, sobre todas las acciones cotidianas. A raíz del mismo tema, Terry Smith explica que, en el contexto actual, la globalización se caracteriza por una "sed de control del tiempo frente a la proliferación de temporalidades asincrónicas” (Smith 20). Es decir, la globalización implica una búsqueda por estandarizar y medir temporalidades que parecieran tener velocidades, magnitudes y ritmos diferentes, además de acelerar la velocidad en todo tipo de acción mediatizada. Esto hace de la simultaneidad de procesos un factor determinante de la economía neoliberal. Por ejemplo, según la página de ventas online Amazon. com, el aumento del tiempo de carga de la página en un segundo podría costar \$ 1,6 mil millones de dólares en ventas anuales (Zumbrunnen), lo que implica que la velocidad desplegada en la interfaz estaría en directa relación con la ganancia o la pérdida económica. Por su parte, cuando Google.com disminuye la velocidad de carga en cuatro décimas de segundo, pierde alrededor de ocho millones de búsquedas (Zumbrunnen), lo que deja ver una estrecha relación entre la velocidad de interfaz, el acceso a la información y el rendimiento económico de la página. Esta manera de relación con el tiempo, según la cual "el tiempo es dinero", se complejiza por las micromagnitudes temporales que se barajan en la actualidad: la red de procesos y simultaneidades se vuelve tan compleja e intrincada que el tiempo parece ser una resistencia a superar constantemente.

Existe un atraso continuo, no necesariamente por la duración de procesos sino por la constante renovación del límite de la novedad. Esto quiere decir que, mientras más inmediatos sean ciertos procesos mediáticos, mayor será la exigencia de velocidad de dichos procesos. Este modo de pensar el tiempo implica que la temporalidad está, una vez más, en constante diferimiento de lo que es el tiempo propiamente tal y su contenido en acontecimientos. No es que el tiempo se acelere, sino que más bien se acelera lo que se inscribe en su transcurso.

La propuesta de diferimiento temporal -desplazamiento o alteración del tiempo- implica la imposición de una estructura racionalizada de representación que se superpone a la experiencia real en el tiempo. Esta voluntad por racionalizar el tiempo y administrarlo mediante diversos sistemas de orden como relojes, agendas, calendario, cartas Gantt, entre otros, permiten dar forma a representaciones del tiempo y generar paralelismos y traslapes que permiten configurar una narración del tiempo. 


\section{La representación del tiempo en la poética de The Clock}

La administración del tiempo es una forma de experiencia del mundo guiada por sistemas de representación de fragmentos arbitrarios que se ordenan en patrones repetitivos. Por ejemplo, las horas escritas en una agenda son las mismas veinticuatro que se repiten cíclicamente en una numeración ascendente de días. Los días son siempre los mismos siete que se ordenan bajo el ítem semana, y así se disponen meses, años, etcétera. El ciclo de veinticuatro horas se va repitiendo como una fragmentación de tiempo bajo una cifra ascendente que se vuelve vectorial. A partir de esto, la posibilidad de representar gráficamente los sucesos que se inscriben en el horario diario permiten un desplazamiento de la temporalidad a elementos que simbolizan un transcurso, lo que permite hacer movimientos y relaciones temporales que no se pueden establecer con el tiempo mismo.

Según la filosofía kantiana, una de las características del tiempo es que la concepción de sus fragmentos es sucesiva, ${ }^{3}$ a menos que sea graficado linealmente, y en tal caso, la simultaneidad de las partes de la línea responde a la emancipación del tiempo de su propia representación. El tiempo bajo ese carácter permite cortar, extender, comparar y coordinar "tiempos" que de otro modo no pueden tomar contacto. Pero, más allá de referirse a la temporalidad real de la experiencia, se trata de un tiempo ficcionado, trasladado metafóricamente a la maleabilidad de la materia. Mediante dicha alienación, el tiempo puede participar como un factor problemático en diversas obras de arte, representaciones gráficas, mapas, entre otros.

Por ejemplo, en la infografía The Daily Routines of Famous Creative People (fig. 2) se representa la administración del tiempo de famosos escritores, músicos, artistas y arquitectos en un esquema que resume actividades cotidianas. A partir de la estandarización de las rutinas y la equivalencia en colores, propone una comparación del modo de empleo del tiempo cotidiano de cada uno de los personajes aludidos, permitiendo establecer una sincronía de las actividades mundanas en contextos epocales muy diversos. Visualmente, solo vemos fragmentos de colores diferentes, ordenados en cantidades y recurrencias que representan el tiempo utilizado para realizar diversas actividades. La representación de las horas de un día tipo se establece de forma lineal horizontal, coordinando el modelo temporal propuesto entre todos los personajes de manera vertical. Así, se genera una analogía mediante el orden de los bloques cromáticos que da como resultado un promedio de todos los días limitado a una rutina, mostrando de modo simultáneo el empleo del tiempo de cada personaje aludido en épocas, países y contextos muy diferentes.

3 El fragmento de la crítica de la razón pura aludido es el siguiente: "Debido precisamente al hecho de que esta intuición interna no nos ofrece figura alguna, intentamos enjugar tal déficit por medio de analogías y nos representamos la secuencia temporal acudiendo a una línea que progresa hasta el infinito, una línea en la que la multiplicidad forma una serie unidimensional. De ella deducimos todas las propiedades del tiempo, excepto una, a saber, que las partes de la línea son simultáneas, mientras que las del tiempo son siempre sucesivas" (Kant 77). 
FIGURA 2

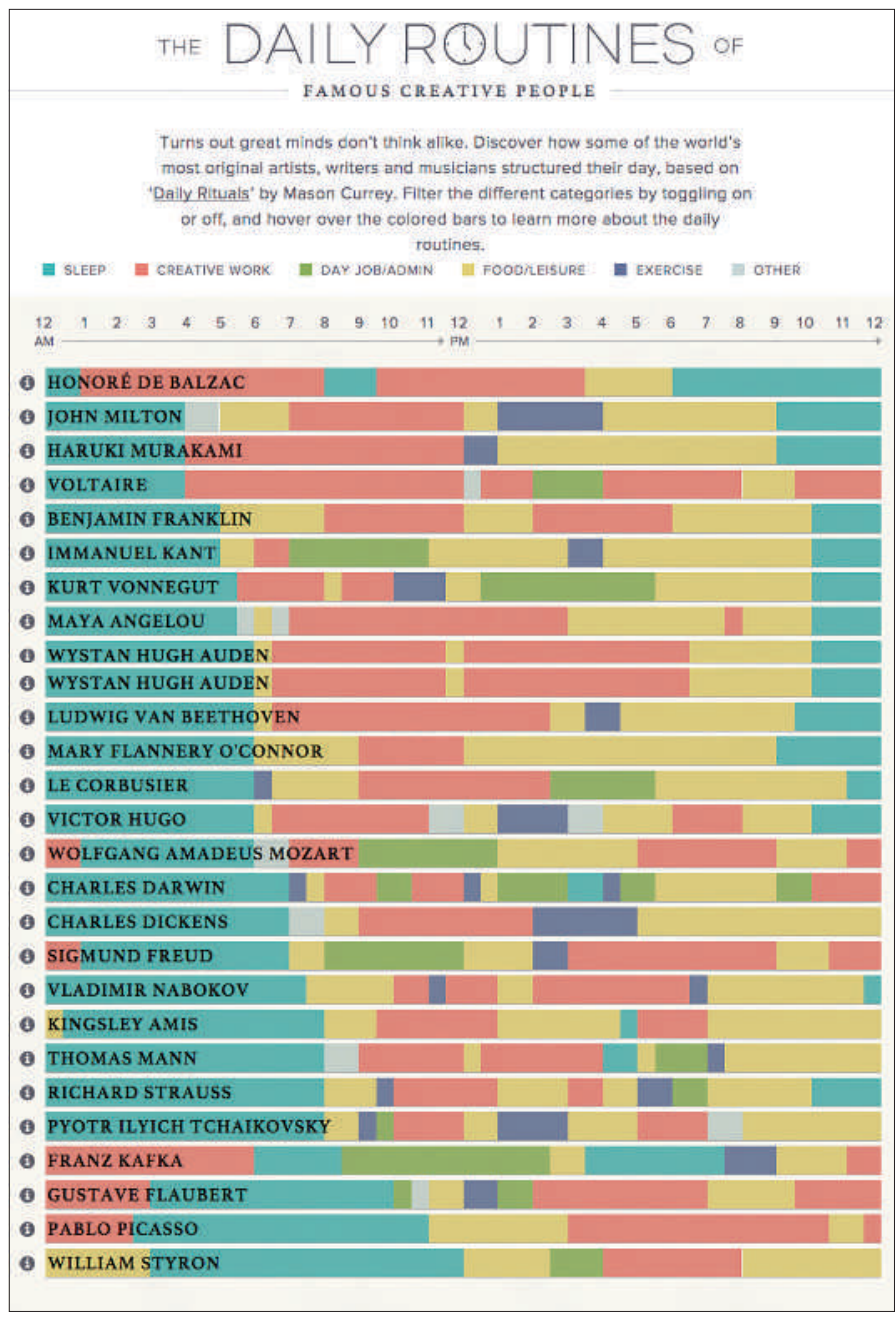

Imagen de la infografía interactiva The Daily Routines of Famous Creative People. Realizado por la agencia de Marketing Distilled, publicado en la web por podio.com. 2015. La imagen está basada en la investigación de Mason Currey "Daily Rituals: How Artists Work", 2013.

Esta manera de representar el tiempo anula la importancia del acontecimiento espontáneo, ya que al pensar el día como un ciclo repetitivo que conduce a un estándar rutinario se anulan los diversos hitos y modos de acontecimiento que trae la diversificación del día a día. El tiempo puesto a disposición de la rutina es un tiempo previamente administrado y familiarizado, por lo que es contenido dentro de las rutas de acciones que lo anticipan. Debido a lo mismo, los sucesos que adquieren relevancia para ser inscritos dentro de un esquema son los que acontecen diariamente, situación 
que deja la novedad fuera de registro. Por su parte, la obra The Clock, implica un modo de representación temporal que, teniendo una lógica lineal -con un comienzo y un final-, se articula también de modo cíclico -el sinfín en el que una vez que termina la proyección, vuelve a empezar-, emulando el modulo fijo y a la vez progresivo del reloj. Así, no es posible percibir la obra en la simultaneidad de sus partes como en la representación gráfica de un tiempo lineal -por ejemplo, tal como lo presenta la infografía antes descrita-, sino en la sucesión segundo tras segundo.

Como describe Amelia Groom en el libro Time. Documents of contemporary art, la obra de Marclay es de hecho un reloj que marca la hora mediante una interfaz diferente a la de los relojes que conocemos. Esto es, cumple la función de medir el tiempo tal como un reloj, pero mediante el formato audiovisual, por lo cual los minutos y horas no son dados cada segundo -no están en todo momento en escena-, sino que se conectan con otras narrativas que interrumpen la exhibición del paso del tiempo en el reloj, mas no lo desfasan del tiempo real. Groom propone:

El trabajo de Marclay se revela como un exacto cronometrador. Estas películas populares nos invitaron a languidecer en la oscuridad, [...] y ser transportados temporalmente, la reordenación - de los fragmentos- a modo de reloj prohíbe tales escapismos al señalar incansablemente cuanto de nuestro propio tiempo estamos gastando frente a la pantalla (20). ${ }^{4}$

Lo que el reloj hace con el tiempo -fragmentarlo-, Marclay lo hace con las películas; así, produce una inconstancia en el ritmo de aparición de las imágenes, manteniendo la consistencia del tiempo dividido en las unidades de horas, minutos y segundos. Marca un tiempo en el que la referencia del reloj se vuelve el eje estructural del montaje -mas no rítmica-, dando cohesión a las radicales diferencias cualitativas de las imágenes utilizadas.

Los fragmentos de película se conectan de manera tal que generan cierta coherencia descriptiva, haciendo nexos visuales, como por ejemplo, en la continuidad de efectos lumínicos y locaciones. También se producen nexos narrativos, como relaciones causales entre fragmentos de escenas diferentes. Y por último, se proponen nexos sonoros, como por ejemplo, el traslape de música incidental y la continuidad de diversos sonidos entre escenas. Todo esto en función de conglomerar la diversidad de fragmentos provenientes de películas y series de diferentes épocas, géneros y formatos, en un todo supeditado a la estructura de medición temporal. La obra, que responde a una estructura de tiempo regular -la del reloj-, se articula narrativamente de forma irregular, haciendo que las alusiones temporales que marcan la hora respondan a la hora local real; a la vez, la aparición de dichas referencias no se da en un ritmo ordenado y uniforme como la del reloj.

4 Cita en idioma original: "Marclay's work reveals itself as an accurate timekeeper. These popular movies invited us to languish in the dark (...) and temporally transported, the clock's rearrangement of them prohibit such escapism by endlessly pointing out how much of our own time we are spending in front of the screen." 
Por ejemplo, en la hora 22 con 15 minutos en The Clock vemos lo siguiente: una mujer escapa en un auto, un reloj de pulsera con la imagen del perro Pluto de Disney, una mujer acostada desnuda, suena la campana de un reloj de muralla (escena en blanco y negro), un hombre camina por el interior de una casa y es interpelado por otro que prende una luz, el personaje de Indiana Jones conversa con una mujer y el diálogo hace la alusión a la espera de cinco minutos, un hombre sentado en un sillón despierta frente a un televisor y mira su reloj de pulsera, un policía grita llamando la atención de alguien con un reloj en el fondo de la escena, una mujer en su cama de noche, Indiana Jones mira un reloj, un hombre sale de un ascensor, corre por los pasillos de una oficina y hace alusión a la premura de algo por suceder, se une la escena de un temblor con el movimiento de los objetos que se encuentran al interior de un tren, un reloj de bolsillo en la mano de un hombre, un auto se detiene, la mujer que escapa en un auto continúa escapando, Al Pacino en un dormitorio prende y apaga una luz y continúa el mismo movimiento lumínico en el corte siguiente, donde una enfermera apaga una luz (escena en blanco y negro). En estos tres minutos de obra descritos, las alusiones al tiempo ocurren en el segundo 17, 21, 55; en el minuto 1:12, 1:26, 1:42, 1:51, 2:07, 2:30, 2:40 y 2:45. Así, la ubicación referencial de la imagen en el tiempo no está ordenada de modo regular y continuo, lo que hace aparecer la estructura lineal del tiempo del reloj en una cadencia que responde a la propia coherencia interna de las imágenes articuladas. Así, si representásemos en una línea el ritmo del reloj tendríamos que dibujar cada segundo perfectamente equidistante del segundo anterior y del siguiente, sin embargo, si dibujáramos en una línea paralela las alusiones al tiempo en la obra de Marclay, los puntos no serían equidistantes, sino más bien desregulados y antojadizos (fig. 3).

Como se ve en el diagrama de estos tres minutos de obra, la línea horizontal recta es la representación del tiempo, subdividida en segundos; los puntos sobre la línea corresponden a las alusiones temporales que se dan en la película, ubicados conforme al segundo de aparición, y la línea sinuosa más baja correspondería al relato visual que vuelve a la referencia temporal sin un ritmo uniforme pero de manera reiterativa. Se genera así una suerte de paralelismo entre la estructura ordenada del reloj y la manera en que la obra remite a este orden mediante su propia disposición interna.

Este desfase o destiempo de la obra con el ritmo constante del reloj, además de evidenciar una emancipación de las representaciones estandarizadas -pero volviendo a ellas bajo un ritmo propio-, trabaja el paso del tiempo como una concepción que se debate entre velocidades y coordinaciones, es decir, el desplazamiento del tiempo a una magnitud y a una relación entre representaciones. Por una parte, está la percepción del tiempo del espectador mediante el extenso período que abarca la obra -que se presenta con una extensión difícilmente experimentable- es decir, para contemplar la obra completa se pone en juego un forzamiento del cuerpo que colinda con la imposibilidad de la experiencia. Pero por otra, está la constante referencia al paso del tiempo según unidades de medida que exhiben constantemente el flujo temporal 
FIGURA 3

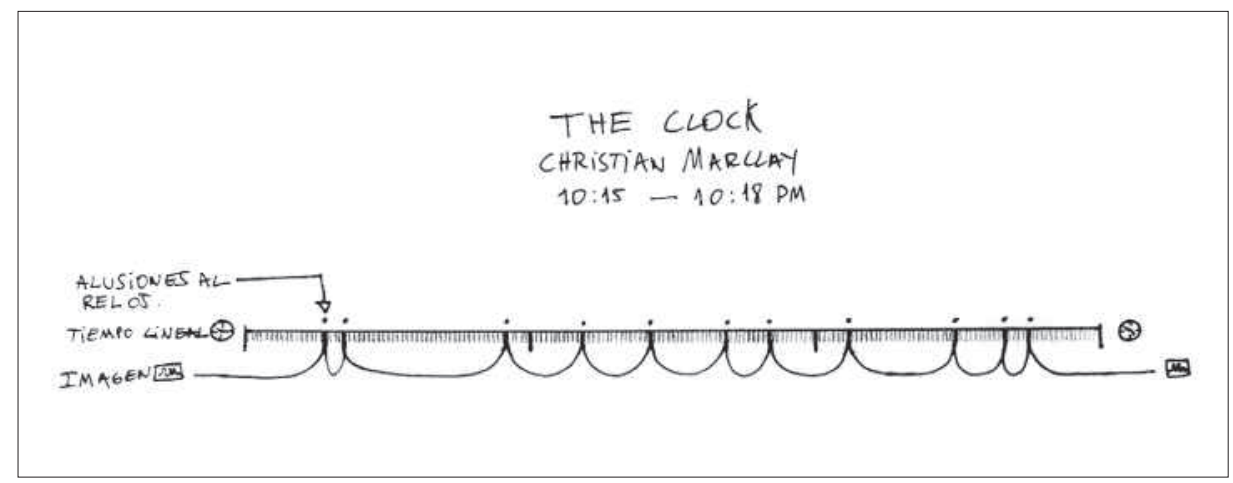

Diagrama de la estructura temporal de The Clock de Christian Marclay, de las 10:15 a las 10:18 pm. Dibujo original.

que se está yendo. Por lo mismo, el espectador entrega su propio tiempo -de vida- a la experiencia del tiempo de obra, lo que paradójicamente coincide en los aspectos formales que lo representan, mas no constituyen el tiempo mismo.

En la obra de Marclay hay una correlación de la imagen con el tiempo real que hace que el tiempo se mida mediante el reloj y mediante el transcurso de las imágenes. Por lo que estructuralmente, la obra no permite adentrarse por completo en la trama específica de cada una de las películas que fueron utilizadas para componerla, ya que en cada momento que la obra refiere al tiempo, está respondiendo a la linealidad temporal que representa. Pero, aun cuando se liguen imágenes muy diversas, que incluso parecen aleatorias, el objetivo final de la obra no deja de ser el de marcar el tiempo fragmentado del reloj, exhibir el flujo continuo del tiempo y mostrarle al espectador cómo es que deja pasar el tiempo frente a sus propios ojos. Ese constante pasar del tiempo de obra, que es a la vez el tiempo de experiencia, constituye uno de los potenciales de sentido más contundentes de la propuesta, ya que pasa del ámbito de la representación al ámbito de la realidad. Al respecto, Lynne Tillman escribe:

Me acuerdo de mi aguda ansiedad viendo el extraordinario vídeo de Christian Marclay, The Clock (2010). Era jueves -15:15, 15:16, 15:17- Estaba viendo pasar el tiempo. Mi tiempo. Estaba pasando, y yo lo estaba viendo. ¿Qué es lo que veo?, ¿para qué estoy viendo? No iba, no pude, esperar el final. ${ }^{5}$

The Clock propicia una experiencia de tiempo mediada por la referencia del reloj, que relega a la obra a ser percibida como un momento de espera en el que el número que codifica la progresión temporal avanza. Esta noción de que el tiempo se nos hace

5 Cita en idioma original: "I'm reminded of my acute anxiety seeing Christian Marclay's extraordinary video The Clock (2010). It was Thursday $-3: 15$ pm, 3:16 pm, 3:17 pm- I was watching time pass. My time. It was passing, and I was watching it. What is this watching, what am I watching for? I wouldn't wait until the end". 
presente en la experiencia de la obra se asemeja a la variabilidad de la percepción del tiempo que examina Martin Heidegger a partir de la exposición del aburrimiento. El autor explica que bajo este temple de ánimo el tiempo parece extenderse, y por lo mismo, buscamos formas de entregar un contenido al tiempo para impulsar su transcurso (Heidegger 112). Esta forma de relación con el tiempo implica que la percepción temporal se vuelve relativa a la experiencia de su contenido; por lo tanto, variable en la consideración de extensión. Bajo este enfoque, la percepción de extensión del tiempo no está relacionada con los parámetros objetivos de medida, ya que un minuto, por ejemplo, dependiendo de las circunstancias en que se experimente, puede percibirse como muy breve o muy extenso. El aburrimiento, entonces, bajo la consideración heideggeriana, evidencia la necesidad humana de buscar formas de llenar el tiempo y hacerlo pasar. Empero, esto se da de forma paradójica, ya que si bien queremos que nuestro tiempo de vida sea largo, en el momento en que la percepción misma del tiempo se dilata llega el requerimiento de acelerarlo. El tiempo bajo, este enfoque, ejerce una opresión en la experiencia, deja vacíos (Heidegger 160), y por lo mismo, bajo el temple del aburrimiento se percibe un tiempo que pareciera estar detenido. ${ }^{6}$

The Clock demarca en su propia cadencia el paso del tiempo. Las referencias al tiempo se dilatan y no enuncian la continuidad segundo a segundo, por lo que la espera de dichas marcas que nos orientan en la medición del paso del tiempo propician la extensión de la experiencia de los lapsos temporales demarcados. El reloj que intenta ordenar la experiencia temporal, dada la particularidad de la obra, incrementa la desorientación mediante los intervalos discontinuos de imagen, extiende la espera y "da largas" o bien detiene la percepción del tiempo en tanto no exhiba la progresión numérica de las horas. Dicho de otro modo, tendríamos una cadencia regular de representación del tiempo en el reloj contrastada con una completamente irregular que responde a la propia coherencia interna de la obra. Por lo mismo, si el reloj es un dispositivo que evidencia en todo momento su fragmentación mediante el ritmo constante de los segundos, esta obra, al integrar esa división temporal en su poética, deja fuera de evidencia gran parte de esos segundos, para aludir a su ciego trascurso mediante hitos irregulares que recuerdan que efectivamente esos segundos transcurrieron. En esos lapsos en que se olvida el paso del tiempo, se problematiza la desaparición de un tiempo irrecuperable. O bien, esos transcursos temporales no representados y exhibidos tácitamente, al mostrar un intervalo de representación temporal, articulan una poética sobre la base de la fuga del tiempo mediante la exhibición de sistemas de medida.

6 "El tiempo no nos sujeta, en cierto modo se retira, y sin embargo, en tanto que nos entrega sólo en forma de plazo a nuestro estar ahí metidos, no nos despide totalmente de sí. Al contrario, con ello revela sólo justamente nuestro estar sujetos a él. (...) No se muestra como transcurriendo ni como imponiéndose, y no obstante se revela. ¿Cómo, pues? De modo que parezca que no está ahí. Se muestra y no discurre: está detenido. Pero eso no significa en absoluto que haya desaparecido, sino que este estar detenido del tiempo es el dar largas más original, y eso significa oprimir" (Heidegger 160-1). 
Entonces, nuevamente surge un aspecto contradictorio en este asunto. Mientras que la progresión numérica de las horas exhibidas son los hitos esperados por el espectador para dar cuenta del transcurso del tiempo, la percepción de los intervalos vacíos de información referentes al tiempo son la experiencia temporal propiamente tal. Es en esos lapsos en que la obra hace presente el tiempo vivido y entregado a su experiencia, más allá de su representación.

En torno a la poética temporal que se articula en la obra, cabe distinguir los modos en que el tiempo puede ser pensado desde la producción. Por una parte, el cineasta Andrei Tarkovsky explica que una vez que se inventó el cinematógrafo se pudo fijar y reproducir el tiempo y "con ello el hombre consiguió una matriz de tiempo real. Así, el tiempo visto y fijado podía quedar conservado en latas metálicas durante un tiempo prolongado (en teoría, incluso eternamente)" (83). Tarkovsky se refiere al tiempo como el contenido anecdótico que ocurre en su transcurso; ese mismo contenido anecdótico es el que se exhibe en la obra de Marclay mezclando un sinnúmero de temporalidades diferentes, una suerte de collage o mosaico de recortes de tiempo que se organizan de manera progresiva. Por otra parte, Gilles Deleuze propone que "todo lo que cambia está en el tiempo, pero el tiempo mismo no cambia, no podría cambiar él mismo más que en otro tiempo, hasta el infinito" (31). Bajo este punto de vista, es impensable capturar y, por ende, modificar el tiempo como tal, ya que el tiempo solo es tiempo y muta solamente hacia un nuevo tiempo. Lo interesante es que la obra de Marcaly se vincula con ambas formas de pensar el tiempo. Esto es, utiliza el registro de la anécdota en el tiempo como un medio para reflexionar sobre la imposibilidad de cambiar su flujo, y así insiste en la alusión temporal desde un desplazamiento -el reloj-, ya no desde la narración que ha sido captada en la imagen cinematográfica, sino desde la solicitud de contexto al coordinarse con el tiempo real. Es en ese gesto, mediante el cual se inscribe la obra en un aspecto administrativo de la vida cotidiana, que se articula un nuevo abandono del tiempo, ya que se evidencia como una efusión inmodificable que aun cuando no se puede desvincular de la vida diaria, no cambia su transcurso conforme a esta.

\section{Poética contemporánea del tiempo en The Clock}

El vínculo que establece The Clock entre imágenes masivas y la hora local del lugar de exhibición invita a reflexionar acerca del requerimiento del arte contemporáneo por situarse en un contexto relacionado con la vida, más allá de una instancia de exhibición. En el contexto actual globalizado, el arte contemporáneo utiliza modelos, procesos e imágenes provenientes de diferentes medios que no necesariamente han sido dispuestos para hacer arte de forma tradicional. Para abordar este argumento, Yves Michaud plantea que el arte contemporáneo retoma temas e imágenes publicitarias, figuras de medios de comunicación y la industria del espectáculo (35). Afirma 
que actualmente el mundo se ha vuelto indisociable de los medios de comunicación, los que no solo lo representan, sino que también lo constituyen del modo en que lo conocemos. A raíz de eso, "Nuestra cultura es una cultura de la copia: el medio es el mensaje y el mensaje el medio" (Michaud 35). El pastiche, el reciclaje y la cita son estrategias de reutilización del imaginario contemporáneo que se ha mediatizado con tal velocidad que los orígenes y autorías se vuelven difusos. Lo importante es la búsqueda de impacto en la imagen. Por lo mismo, lo contemporáneo está definido por una estetización de todo lo que compone la vida cotidiana, la publicidad, las mercancías, los medios de comunicación y el arte. Es bajo este ámbito que Michaud traza el itinerario del triunfo de la estética, donde el arte se gasifica, filtrándose a todas las áreas de la vida:

Es como si a más belleza menos obra de arte, lo artístico se expandiera y lo coloreara todo, pasando de cierta manera al estado de gas o de vapor y cubriera todas las cosas como si fuese vaho. El arte se volatilizó en éter estético, recordando que el éter fue definido por los físicos y los filósofos después de Newton como medio sutil que impregna todos los cuerpos" (Michaud 10).

Este fenómeno de vaporización y difusión, que metafóricamente se propone como el arte en estado de gas, ${ }^{7}$ sucedería por la desaparición de la obra como un objeto de la experiencia estética. Michaud planeta que lo que sucede es un desplazamiento de la obra de arte por dispositivos y estrategias que generan experiencias -efectos artísticos-; de ahí el diagnóstico de pérdida de los límites, ya que no existen términos bajo los cuales los dispositivos y soportes actuales del arte pertenezcan exclusivamente a la disciplina. La obra de Marclay utiliza un imaginario contemporáneo proveniente de la cultura de masas, desde la estrategia de la apropiación para poner en un lenguaje cotidiano una poética que reflexiona en función del paso del tiempo y la marcha del presente de cada uno de los espectadores que se enfrentan a ella. La propuesta plástica de la obra implica precisión en la elección y un montaje de imágenes realizadas bajo la industria del espectáculo -cine y televisión-, por lo que más que el carácter inédito de la visualidad de la obra, se articula un lenguaje que problematiza el dispositivo del tiempo, desdensificando el carácter material de lo exhibido. Las imágenes funcionan anacrónicamente, aun cuando de forma paradójica demarcan el tiempo.

La extensión de la obra supone una dificultad para experimentarla completa: con el dato numérico de la duración -veinticuatro horas-, el espectador intuye que podrá acceder a un fragmento de la obra, ya que requiere bastante tiempo verla en su totalidad.

Desde una poética similar a la de Marclay, las obras 24 Hour Psycho de Douglas Gordon (1993) y Empire de Andy Warhol (1964) articulan tanto la extensión

7 Un argumento similar es el que se plantea con el concepto de arte en estado líquido a partir de la propuesta de Zygmut Bauman, que tiene que ver con valores similares de desmaterializción y quiebre con la función tradicional del arte. 
temporal en la obra, como la apropiación de un imaginario masivo y popular pero desde un enfoque diferente. La propuesta de Gordon consiste en la intervención de la famosa película de Alfred Hitchcock Psicosis (1960), de modo que extiende el tiempo de reproducción a un total de veinticuatro horas. Por su parte, la propuesta de Warhol consiste en el plano estático durante ocho horas del edificio Empire State de Nueva York, en que lo único que acontece es el cambio en la luminosidad. Ambas obras generan una experiencia oprimida del tiempo a partir de la larga duración que implica su exhibición, tal como en The Clock, poniendo en crisis las posibilidades de experiencia de la totalidad de la obra. Desde ese lugar, las tres propuestas articulan la desorientación desde la exposición de extendidas cantidades de tiempo, tensando las posibilidades de representación temporal versus la experiencia. Por otra parte, las propuestas de Gordon y Warhol problematizan el acontecimiento cinematográfico al ralentizar la exhibición, o bien, al dar la ilusión de que "nada pasa". Mientras ambas poéticas "dan tiempo" a la imagen al dilatar la acción, Marclay se encarga de sobrepasar el acontecimiento a tiempo real, esto es, una vez que exhibe un fragmento de escena cambia el plano, sin dejar que el espectador comprenda una trama que no tenga relación con el paso del tiempo del reloj. Por lo mismo, si desde el lenguaje audiovisual estas tres obras exhiben imágenes de difusión masiva -desde las referencias del cine, la televisión e íconos populares-, es la coordinación de dichas imágenes con el tiempo real la que permite que la obra de Marclay imponga un tiempo propio.

Con seguridad, la mayoría de los espectadores que han visto The Clock, 24 Hour Sycho o Empire solo han visto un fragmento de obra, el que aun así "surte el efecto" del compromiso temporal que implican. Es probable que la experiencia de ver estas obras en su totalidad sea extenuante y letárgica, extrapolando la experiencia de la fracción, pero, aun cuando no se vean completas, ya sea desde la coordinación con el reloj o desde la extensión temporal, las tres propuestas implican un cuestionamiento del modo en que el tiempo se percibe alterado por los medios que lo reproducen. Asociado con esto, The Clock exhibe un fluir temporal que indica y se sincroniza con una temporalidad habitual, y de este modo hace que la obra en sus distintas etapas funcione de la misma manera, demarcando un tiempo mediatizado y sistematizado, alterado por la técnica.

Es importante recalcar el modo en que la propuesta de Marclay exhibe, mediante un lenguaje contemporáneo, una supuesta disponibilidad temporal como característica de nuestra época. Sin embargo, problematiza la imposibilidad de experimentarla, o bien, el letargo que implica la espera de la demarcación temporal que propone. En ese sentido, el tiempo no se encuentra en la obra, sino más bien en el lugar de encuentro entre la obra y su experiencia, en el sopor de contemplarla. La poética propuesta en de The Clock, se vincula con el transcurso del tiempo del mismo modo en que cualquier medio técnico intenta sujetar el tiempo, es decir, desde el fracaso por contenerlo. Por último, se puede definir que la poética temporal de esta obra como acontecimiento en el tiempo -como obra de tiempo- problematiza en su propio acontecer la eman- 
cipación del tiempo respecto de todas sus estrategias plásticas. Por lo mismo, puede problematizarlas desde esta consabida independencia, ficcionando una suerte de "contención del tiempo" que, más allá de representarlo, ejercita el diferimiento entre el paso del tiempo y el acontecimiento de obra. He aquí entonces una característica que enuncia una estética contemporánea del tiempo, según la cual la obra trabaja con un tiempo que se emancipa de todo medio de contención, de toda forma de representación y de toda posibilidad de experiencia.

\section{Referencias}

Attali, Jacques. Historias del tiempo. Ciudad de México, Fondo de Cultura Económica, 2001.

Deleuze, Gilles. Kant y el tiempo. Buenos Aires, Cactus, 2008.

---. La imagen-tiempo: estudios sobre cine 2. Buenos Aires, Paidós, 2009.

Distilled. The Daily Routines of Famous Creative People, 2015, https://podio.com/site/ creative-routines

Elias, Norbert. Sobre el tiempo. Ciudad de México, Fondo de Cultura Económica, 2013.

Groome, Amelia ed. Time. Documents of Contemporary Art. Cambridge, MIT Press, 2013.

Heidegger, Martin. Los conceptos fundamentales de la metafísica. Madrid, Alianza, 2007.

Kant, Immanuel. Crítica de la razón pura. Madrid, Taurus, 2006.

Michaud, Yves. El arte en estado gaseoso. Ciudad de México, Fondo de Cultura Económica, 2009.

Smith, Terry. ¿Qué es el arte contemporáneo? Buenos Aires, Siglo xxi, 2012. Impreso

Stiegler, Bernard. La técnica y el tiempo. La desorieniación. vol. 2. Gipuzkoa, Editorial Argitaletxe Hiru, S.L., 2002.

Tarkovsky, Andrei. Esculpir en el tiempo. Madrid, España, Ediciones Rialp S.A., 2008.

Tillman, Lynne. "Boredom and Death: Two Sides of the same Coin"?, Frieze, n 153, 12 de mar. de 2013, http://www.frieze.com/issue/article/marking-time

Woodcock, George. "The Tyranny of the Clock". Time. Documents of contemporary art. Ed. Amelia Groome. Cambridge, , MIT press, 2013.

Zumbrunnen, Adrian. "6 Tips for Sharing how Users Perceive Time”, Fastcompany Design. 22 de ene. de 2016, http://www.fastcodesign.com/3055636/6-tips-forshaping-how-users-perceive-time? partner=rss

Enviado: 20 noviembre 2017

Aceptado: 20 junio 2018 